\title{
Managing affect in learners' questions in undergraduate science
}

\author{
Helena Pedrosa de Jesus \\ University of Aveiro, Portugal \\ Mike Watts \\ Brunel University, London
}

For publication in Studies in Higher Education

\begin{abstract}
This paper aims to position students' classroom questioning within the literature surrounding affect and its impact on learning. The paper consists of two main sections. First, the act of questioning is discussed in order to highlight how affect shapes the process of questioning, and we describe a four-part genesis to question- asking that we call CARE: the construction, asking, reception and evaluation of a learner's question. This work is contextualised through studies in science education and through our work with university students in undergraduate chemistry, although conducted in the firm belief that it has more general application. The second section of this paper focuses on seven teaching strategies to encourage, 'scaffold' and manage learner's questions, based here upon the conviction that university students, in this case, learn through questioning, and that an inquiry-based environment promotes better learning than a simple 'transmission' setting.
\end{abstract}

\section{Introduction}

Our starting point is the act of asking a question. This act spans Bloom's (1956) traditional triad of the cognitive, affective and the conative dimensions to learning, involving intellectual, emotional and behavioural components to shape and pose a question. Here, we focus in particular on questions asked by learners in natural, real-life contexts, and upon the role of feelings and emotions during this process. We discuss briefly the work in this area and then look toward ways that teachers and learners can manage the process of enabling and supporting learners' questions, not least through understanding the emotions involved. Our intention is to promote a deeper understanding of the nature, theory, and practice of the questioning process and students' resultant learning. We illustrate the directions of the discussion by drawing upon some of our own original research studies, in particular where undergraduate programmes have emphasised students' own questioning. We are also interested to propose ways in which teachers at this level can mange the affective issues related to questioning and, again, bring our own syntheses of experience to bear. On the whole, teachers - and university teachers are no exception - expect to ask rather than encourage 
a proliferation of questions 'from the floor'. In the final section of the paper we describe the use of learners' questions as a platform for inquiry-based learning and other modes of instruction, and draw out the instructional implications of this body of research on learning.

There is a contentious view that '...recognition and management of emotions are not seen as the business or even the concern of the higher education profession' (Mortiboys, 2002, p.7). However, simply ignoring the powerful role emotions play within the higher education system does not diminish their impact. Emotions have the power to render intellectual endeavour as futile, which can result in withdrawal from a task (indeed the course or from higher education altogether) or, at the other extreme, to motivate and enthuse learners to progress. In essence, 'affect surrounds cognition' (Authors, 2003, p.1046), and it is this perspective that drives theorists such as Gardner (1993) and Goleman (1996) to dismiss the once established conviction that intelligence tests alone can validly represent human mental capacities. These views led to the evolution of the concept of emotional intelligence (first coined by Salovey \& Mayer, 1990), which Goleman (1996) argues can be taught to students, '...giving them a better chance to use whatever intellectual potential the genetic lottery may have given them' (p.xii). Meizrow (2000), in turn, makes the link between feelings and values and the capacity for transformational learning to take place. Alsop (2005) strengthens this to argue that affect plays a fundamental role in learning:

Some emotions such as joy, excitement, interest, enthusiasm, curiosity and hope can act to enhance cognition, while others (such as fear, anxiety, boredom) might serve to deaden curiosity and insight (p.48).

\section{Emphasising the affective in question-asking}

Our acronym for this four-part questioning process is CARE (Constructing, Asking, Receiving, Evaluating). In this section of the paper we discuss ways in which the process can be, and has been, 'scaffolded', where learners' questioning is supported, managed and improved: the ways that learners' can develop through assisted performance. These are strategies that have been tried and tested within our programmes of research and development over the last decade (Authors, 2006), principally with teachers and learners in higher education, and within the natural sciences.

In Graesser \& McMahen's (1993) work there are three stages to generating a question: (i) the detection and awareness of a conflict in knowledge and understanding; (ii) the 
articulation of this in words, and then (iii) the expression of these words in a social setting. These authors call the stages 'disequilibrium detection', 'verbal coding' and 'social editing'. In our own work ( $\underline{\text { Authors, }}$ 2005a) we have broadened this to a fourpart process, to add a 'feedback stage': (iv) acknowledge learners' affective responses to the asking of questions in real-world classroom contexts.

\section{(i) Constructing questions}

Disequilibrium, or 'variance' (Marton \& Booth, 1997; Moon, 2005), signals conflicts in knowledge: puzzlement, curiosity, perplexity, doubt, challenge, wonder, incongruity. Variance of this kind is an 'adult' form of Piagetian individual constructivism, the core of which is driven by the processes of equilibrium and disequilibrium (Piaget, 1971). First comes the assumption that the ideal human end-state entails a perfect match (an 'equilibrium') between our mental schemes and the physical and social worlds we encounter. While perfection is approximate in most cases, and may never actually be attained, people in a state of equilibrium are generally seen to be satisfied with their modes of thought. We are frequently faced, however, with disturbances: new events or situations that cannot be fully handled by existing understandings. This creates an imbalance between what is understood and what is encountered. Awareness of shortcomings in our existing thinking produces dissatisfaction so that 'dis-equilibration' ensues, an uncomfortable state sometimes referred to as cognitive conflict. People then attempt to reduce such imbalances by focusing on the issues that cause the disequilibrium, and develop new thoughts, ideas, understandings - or adapt old ones until equilibrium is restored. Through these processes, of accommodation and assimilation, we adopt more sophisticated modes of thought that serve to eliminate the shortcomings of the old ones and, having done so, we are then considered to have developed ourselves and improved the quality of our thinking.

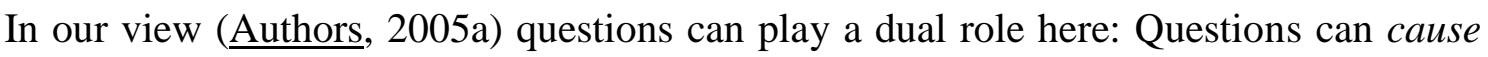
variance, unsettling any previous match between external experience and internal representation, and so prompting disequilibrium. On the other hand, variance can be caused by other mechanisms but can then prompt a series of questions. Moreover, a simple cognitive view of disequilibrium is insufficient. It is clear that feelings of satisfaction, dissatisfaction, comfort and or discomfort, about states of thought or about anything else, are emotional, affective issues and not just cognitive ones. So dissatisfaction, or discomfort, with new incoming elements of information is an 
emotional state. When a student sits in a lecture and is presented with small, medium or large variations to what they already know and hold meaningful, they will experience a range of small, medium or large emotions. These can be positive, negative or some combination of both. So, for example, small feelings of perplexity and apprehensive doubt might creep in as the lecture is being presented, even though these could also be accompanied by feelings of some appreciation of how the new ideas might fit together for the lecturer - even if they feel mildly alien to the student.

There is no doubt, too, that variation can arouse quite strong emotions, 'hot' emotions such as frustration, fear, revulsion, pleasure, hope and joy. It is not news to point out that people can object very strongly to what they perceive as unpalatable, insensitive, drastic or offensive ideas that are radically at odds with their own. In so far as these emotions, positive or negative, then lead to the formulation and asking of a question, they involve an element of action as well. Elsewhere, it has been argued (Authors, 2003) that inherent to the learning process is the need to move from the familiar to the unfamiliar, which has the potential to elicit a vast range of emotional reactions (Cartney \& Rouse, 2006). Claxton (1991) makes the point that:

Learning is generally a risky business because it means moving out from the safety of the known into the unknown and the controlled. [...] The involvement of emotion in learning, especially any that involves personal risks of the kinds described, is inevitable (p99).

\section{(ii) Asking the questions}

Both the processes, 'verbal coding' and 'social editing', can also invoke feelings. Questions do not always arrive fully formed at the point of utterance, ready for the asking. Graesser \& McMahen's (1993) study suggests, for example, that questions do not surface where this involves too much mental effort, or when it is socially awkward to ask them. Many people have had the experience of wanting to ask a question but of not doing so. This may well be for many reasons, not least because they feel the form of the question is inappropriate (it appears naïve or unduly complex), or they resist asking the question to avoid personal embarrassment or social ridicule. The upshot here is that, even if there is awareness of disequilibrium, a knowledge gap, perplexity, doubt, wonder, etcetera, the learner may nevertheless override these feelings and resist 'verbal coding', the articulation of a question at that point. The feelings invoked by doubt and perplexity may not allow the person, science undergraduates in our own case, to give 
full shape to this - in what might emerge as a satisfactory question. When in this position, it is not uncommon for even the bravest questioner to begin to articulate an early question prefaced by "Can I ask you something?", "I know this might sound naïve, but ...", "This might sound a bit silly, but ..." or "I haven't quite got this question right, but ...”.

The process of 'social editing' provides another series of barriers, particularly in lecture and classroom situations. As Marbach-Ad \& Sokolove (2000) suggest, few questions are commonly asked, because teachers often dislike and inhibit students' questionasking. Dillon (1988) indicates that students are more likely to ask questions to other students than to their teacher. Teachers feel vulnerable when there are a large number of questions coming from the audience - it is often much easier to teach, to lecture, without the distraction and delay of having to deal with a plethora of interruptive questions. Instructional models, then, influence student questioning and lesson structures, so that the classroom environment itself can discourage question-asking (Pizzini \& Shepardson, 1991). Nor do any students, it seems, want to call attention to themselves (Good, Slavings, Harel, \& Emerson,1987), and asking questions in class can generate both feelings of exposure and vulnerability (Authors, 1997). A large-audience format is much more daunting than small-group work; a raked lecture theatre more inhibiting than a comfortable tutorial room; a PowerPoint lecture more restrictive than a participative role-play session. Putting a hand up in a large auditorium brings a multitude of eyes to bear on the question-asker and, with this, a level of scrutiny that is often easier avoided. One study of student questions in the context of tutoring sessions found, unsurprisingly, that student questions were 240 times as frequent in tutorial settings as in lecture room settings (Graesser \& Pearson, 1994).

Moreover, Good et al.'s (1987) notion of passivity suggests that students who perceive themselves as low achievers have learned to become less involved in class work, to be non-question askers. In addition, high achievers are sensitive to the cost of question asking - the cost of asking what appears to be a stupid question.

\section{(iii) Receiving responses}

Sadler (1989) was one of the first theorists to highlight the fundamental role that feedback plays in learning at any stage. In our case, the responses that students receive to their questions shape their future actions. Lemke (2003) is critical of much classroom interaction as consisting simply of 'IRF triplets', where teachers Initiate dialogue, 
usually by asking a question (often to one or two students in the group), where students then $\boldsymbol{R}$ espond in some fashion, and then the teacher replies with various forms of Feedback. Lemke argues that this limited, formulaic, question-and-answer format makes up some $70 \%$ of all classroom discourse, certainly within secondary schooling and into higher education, giving rise in all probability to Graesser \& Pearson's (1994) observation that teachers typically ask $96 \%$ of the questions in a classroom environment. By contrast, the cycle for a student-initiated question can be much more complicated and uncertain (Dillon, 1988). For example:

1. The student bids for the floor through attracting the lecturer's attention (usually by putting up his or her hand)

2. The student seeks permission from the lecturer to ask a question

3. The student asks the question

4. The lecturer then responds by

(i) replying through answering the question; asking a counter-question; redirecting the question, re-formulating the question, or

(ii) making no reply and moving on

5. The student acknowledges any reply (as opposed to evaluating it - that is typically the lecturer's domain)

6. The lecturer moves on (often asking another, seemingly unrelated, question).

Step 4(i) above is generally the most likely, where the teacher makes a genuine response to the student's question. Feedback is conceptually complex and a logistical challenge for classroom teachers at all stages in the education system and, unsurprisingly, it is enormously variable from teacher to teacher, classroom to classroom. At the most basic level, the teacher's response must address the student's desired level of knowledge (Sadler, 1989) and, as within all classroom contexts, there will be degrees of success in realising this. The answer may or may not meet the questioner's 'knowledge gap'; the tone of the response may or may not meet the questioner's affective needs.

Orrell (2006) makes the case that '[feedback] can be deeply affective, exercising a profound impact on students' constructions of themselves as learners and their motivation in future learning (p.44). There is good research to indicate that negative feedback results in decreasing levels of motivation. For example, Shim \& Ryan (2005) suggest that emotional reaction to feedback is based on individuals' goals (Beaty, Gibbs \& Morgan,1997; The Assessment and Learning Research Synthesis Group, 2002), and/ 
or their self esteem and self efficacy (Young, 2000). When either the tone or content of the response is perceived to be negative or unfair, students with medium to high selfesteem commonly direct more anger than distress at the teacher, rather than inwards on themselves, whereas students with low self-esteem are more likely to internalise the feedback as a reflection of their own failings.

Young (2000) describes the impact feedback has on a student's sense of self as both potent and risky, and that this is accentuated in the case of mature students, particularly where assessment is a key part of the learning context (May \& Bousted, 2004). Young takes the position that if a student enters a learning context with medium to high selfefficacy then they are better equipped to see constructive criticism as a challenge and as a means of development, whereas those students subjected to the same conditions but with low self-efficacy are more likely to experience feelings of defeat and failure.

\section{(iv) Evaluating the process}

The feedback loop is only completed once the student has reflected and acted upon it (Smith \& Gorard, 2005; Sadler, 1989). The teacher's response can be seen as positive, negative or neutral. There are two parts to this: (i) Does the teacher's response 'work'? Does it satisfy the initial question? And (ii) Is questioning an activity to be repeated through encouragement, or not?

There are secondary effects, too. As a group of students interact with a teacher, they watch each other, they react to the way their peers are treated. When a friend or colleague's questioning behaviour is rewarded, the observers are more likely to reproduce that rewarded behaviour. Questions receiving positive teacher feedback will encourage others in the group to ask their own questions. Should the questioner receive a negative, inhibitory response, an example of 'vicarious punishment', the observers are less likely to reproduce the same behaviour. This includes the notion of peripheral participation (Lave \& Wenger, 1991). For example, a student asks the teacher a range of questions for which they receive positive answers and encouragement. A more inhibited student on the edge of the group then moves forward and is emboldened to ask further questions, building on and from those asked by the first. This exemplifies differences between 'guided participation' and 'peripheral participation'. Much rests on the power of the teacher and the first student to either support the newcomer into the community or to exclude and keep them on the periphery. 


\section{Scaffolding the CARE process}

To support the CARE process, we set this out as seven strategies, as follows:

\section{Strategy 1: Design for social activity and interactive learning}

Cooperative learning activities such as group investigations, team and project-based learning enable the integration of interpersonal competencies with academic skills, so that some of the affective barriers to questioning can be reduced. Chin, Brown \& Bruce (2002) emphasise the importance of questioning between peers, noting that this is a way to generate productive discussions, where the students become involved in an interested and genuine way, supporting each other, leading to the comprehension of concepts and ideas. That is, enabling effective models and examples through direct peer-modelling within group interactions provides emotional scaffolding for such social questioning. In our work (Authors, 2005b) we monitored and investigated students' questions while they worked as members of a team, designed as mini-projects in undergraduate chemistry. Through this work we showed that it is very possible to create a questioning environment where the asking of questions (and receiving answers) becomes an integral and 'easy' part of everyday transactions between teachers and students. It is possible to change the atmosphere of the conventional lecture and tutorial sessions - here in the teaching and learning of undergraduate chemistry - to create a shared mood of understanding, motivation and conceptual engagement. These mini-projects created conditions that allowed the relaxed formulation of students' questions, and the formulation of questions between peers. There were several instances where questions from one person in the group stimulated the formulation of questions by others within the group.

In this way we demonstrated that inquiry-based group-work is an important learning experience since it enabled the exploration of theoretical ideas and conceptual change in a peer-supportive atmosphere. Questioning became creative, shaping the skills for continued intellectual development, and contributed to students' engagement in the discipline. Moreover, this approach brought an increase of interaction between teacher and students, an increase in the affective confidence and trust of the students in the asking of questions, and therefore an increase in the quality of classroom interactions in the learning and teaching of chemistry. As Scardamalia \& Bereiter (1993) point out in their work on creating 'knowledge-building communities', the capacity to acquire 
expertise and high level reasoning can be fostered be giving students clear agency in learning, by allowing expression of personal and collective motives for learning. Students need to perceive themselves competent in self- and group-managing their learning and coming to 'affective terms' with new knowledge.

Good et al. (1987) suggest a cautionary rider to all this: that low achievers, in any part of the educational system, learn to become less involved in class work, to be nonquestion askers, not least because of the fear of ridicule. Moreover, high achievers might also stay silent because they are sensitive to the cost of asking questions - the cost of asking what appears to be a stupid question (Van der Meij, 1994) - the palpable fear of failure. This appears to leave question-asking to students within the middle ground. We have made no judgements of achievement in our own studies, but can still see some of these issues of emotional 'cost-driven passivity' in what is said. At the mild end of emotional impact, question-asking may be hindered, at the more dramatic end, frustrated completely. As Salmon (1988, p.27) says:

New understanding is, potentially, threatening ... To be confronted with unfamiliar knowledge can result in a feeling of complete bewilderment. You feel totally at sea, lost, without anchors of any kind, unable to relate what is being offered to personally meaningful interpretations. This is the experience of being unable to engage with learning because it is impossible even to formulate a question.

\section{Strategy 2: Foster 'intentional curiosity' and critical questioning}

Over time we have amassed evidence that questions can structure learning through clarification of intent, fact-finding, grasp of principles, and the explicit and tacit organisation of the learning to be done (Authors, 2005). Like Fisher (1990) we see the process of question-generation and, in particular, the design and use of quality questions, as exercises in critical thinking and in the development of critical thinking skills. As Maiorana (1992, p.5) says:

The purpose of critical thinking is to achieve understanding, evaluate viewpoints, and solve problems. Since all three involve the asking of questions, we can say that critical thinking is the questioning or inquiry we engage in when we seek to understand, evaluate or solve.

In our work (Authors, 2005b), for example, we have delineated students' 'integrative questions', which we described as entailing the reorganisation of concepts into novel patterns, hypothesising new applications or principles, attempting to reconcile understandings, resolve conflicts, track in and around complex ideas and their consequences. That is, critical thinking implies a clear propensity to ask challenging 
questions and that students' questions foster higher-order cognitive skills (HOCS) (Zoller, 2001).

As Hobson (2004) says 'critical thinking is the art of asking questions'. Browne \& Keeley (1998) take this a step further by defining critical thinking in terms of the awareness of and ability to ask 'critical questions', such that critical thinking is (p.2) the:

(i) Awareness of a set of interrelated critical questions

(ii) Ability to ask critical questions at appropriate times, and

(iii) Desire to actively use these critical questions.

In contrast to Browne and Keeley's first point, our own view is that there is no unique set of critical questions so much as a questioner's disposition to be critical. A simple 'Why?' delivered at the right moment with the right intent can be as critically coruscating as the most complex and detailed question delivered at an inappropriate point.

An important issue here, though, is that critique of itself need not always be negative. There can clearly be adverse effects to receiving critical comment or questions about personally held thoughts and ideas, and there is a need to manage these effectively. Often, the criticality of questions lies in the context of the question, and our own work explores a range of classroom episodes so that this critical intent, and any overt stigmatisation, can be identified (Authors, 2011, in preparation). We also suggest strategies in which university teachers can manage and 'orchestrate' their sessions to accommodate such questions. The atmosphere needs to be sufficiently robust to allow an appropriate level of 'give-and-take' in discussions and debate, while being sensitive to the possibilities of any conflict, discomfort or distress.

\section{Strategy 3: Orchestrate differentiation}

There have been many interpretations of a Vygotskyan zone of proximal development (ZPD). For example, Kozulin (2003) sees it as a way to describe learners' development through assisted performance. This implies not only that there is assisted learning but also that the assistor is sensitive to the level of assistance needed by the learner. In the case of teachers, they not only know but can direct the level at which they offer their knowledge and, meanwhile, adhere to outcomes and achievement levels and standards against which they are operating. The idea is not to teach each student exclusively 
according to his or her preferences but to look for a balance in approaches to learning and teaching. If the balance is achieved, students will be taught partly in a manner that they prefer, which leads to an increase in comfort and willingness to learn. They will also develop strategies to cope with teaching methods that cross their preferences and so maximise their chances of learning. Our work (for example, Authors, 2004; Authors, 2006) has shown that:

(i) Students with different learning styles ask different kinds of questions

(ii) Different forms of teaching fosters different kinds of question-asking, and

(iii) Different modes of response to student's questions generates different levels of motivation and engagement.

In our work (Authors, 2005b) we observed that students with distinct learning styles have particular questioning behaviours. Thus, learners probably have intrinsic characteristics that lead them to ask different numbers and different kinds of questions. On the other hand, distinctive teaching strategies also lead students to ask different types of questions. Ways of teaching and ways of responding to students can generate different kinds of questions (Authors, 2006). For example, conventional teaching, lectures, are centred on the teacher and only a few students have the confidence to raise questions from the audience. Probably due to the rhythm and type of the class, students have little time to ponder in order to ask high-level questions. To some extent, the same happens with seminars and tutorials where students, under the gaze of the teacher, may be inhibited by their peers.

Moreover, as we have noted above, small-group work, chemistry laboratory classes and prepared 'question classes' (Authors, 2005b) are more geared to being student-centred, so students have more time and opportunity to raise questions. There are more openings for solving students' conceptual difficulties, particularly where students arrive with previously prepared questions. In this type of class, learners have time to think, compare, analyse, and reflect. Hence, students are more able to operate within their 'comfort zone', with familiar and comfortable aspects of the questioning environment, and higher-level questions are likely to be raised. The same happens with laboratory classes, since the student can prepare his/her lab work at home.

Strategy 4: Ensure that 'learning feedback' becomes a constructive social experience Yorke (2003) highlights the role of feedback to learners as: 
critically important for student learning. Without informative feedback on what they do, students will have relatively little by which to chart their development (p.483).

As Higgins, Hartley \& Skelton (2002) point out, the provision of timely and personalised feedback is important. Askew \& Lodge (2000) adopt a broad definition of feedback to include 'all dialogue to support learning in both formal and informal situations' (p. 1). Juwah et al. (2004) and Nicol \& McFarlane-Dick (2004) have composed seven principles of good feedback practice, which are as follow:

1) Facilitates the development of self-assessment (reflection) in learning;

2) Encourages teacher and peer dialogue around learning;

3) Helps clarify what good performance is (goals, criteria, expected standards);

4) Provides opportunities to close the gap between current and desired performance;

5) Delivers high quality information to students about their learning;

6) Encourages positive motivational beliefs and self-esteem; and

7) Provides information to teachers that can be used to help shape the teaching. (Juwah et al., 2004:2)

Our focus here is on the affective elements in, for example, the sixth principle above. In our work (Authors, 2005b) we have discussed the creation and adoption of strategies for teaching and learning that explored ways to stimulate active questioning by improving the quality of positive classroom interactions. This entailed the use of teaching based on feedback to students-generated questions, both through small group-work tutorials and regular lectures and large class sessions. In order to improve students' motivation and stimulate their curiosity, lectures have been adapted to respond to questions on selected topics of wide scientific, technological and social interest. To further stimulate engagement, quantitative analysis and discussion of selected case studies were used, together with the organisation of laboratory classes based on selected enquiry-based experiments, planned and executed by students.

\section{Strategy 5: Foster metalearning}

Schon's (1987) distinction between 'reflection in action' and 'reflection upon action' implies not just a time difference in the points of reflection but also a form of hierarchy. 'Reflection in action' takes place within the flow of experience, at the time that this 
happening. It is reflection from the midst of the flow, of immersion in the action, at the time of the action. In this sense, questions raised at this instance would be immediate and spontaneous. 'Reflection upon action' takes place at some later point, after the specific experience, the action, is over. However, this need not just be a review of the action but might also be a review of the reflections developed at that time. In this way it can be a reflection upon reflections, and so can represent a second-order process. Questions at this point come after a period of delay and are likely to be more deliberated and 'shaped'.

Reflective questions (Authors, 2005c) are where a clear amount of 'internal contemplation' has taken place, usually expressing judgments, guiding actions, expressing feelings, beliefs, about issues. Curzon-Hobson (2003) makes the point that adopting a suitably critical stance in university studies involves an 'inquiring and reflexive disposition'. One mechanism for generating reflective questions has been to ask students to explore these feelings and emotions through a journal or a diary during the course (Authors, 2000; Authors, 2004). We articulated some early questions as clearly as possible, with the students involved, and then allowed the respondents to formulate their own along the way. We set this out as:

We are interested in two current or (freshly) recent episodes in your learning: (i) where you find some learning (relating to a particular topic or some aspect of your work) to be intellectually challenging but where you seem to be winning the 'struggle for understanding', and (ii) where the intellectual challenge seems immense but where, this time, you are (or have recently been) experiencing blocks or barriers which seem insurmountable. Please frame your responses by asking yourself a series of questions, for example: 'What happened in episode 1'? In your responses please outline briefly the topic or task of each episode, describe some of the emotions you experienced as you were working, and what it was in particular that gave rise to these feelings. Please describe, too, how you dealt (if necessary) with these feelings, what strategies you have for controlling or shaping your feelings during episodes such as these.

In our view (Authors, 2005b) self-reflective questions might include the following:

1. Something is happening that I can't quite understand. Is it usual? What is it about?

2. Is what I am doing appropriate at this moment in time? 
3. Do I need to alter, amend, change what I am doing in order to adjust to changing circumstances to 'get back into balance'?

4. If I am not on the right track, what are the better ways of doing this?

5. To whom do I need to talk to come at this in a better way?

Being intentionally reflective is seen in a number of theories as an integral part of the processes necessary for effective, and affective, learning, because it engages learners in active thinking - envisioning their learning in order to improve future achievements. In this work (Authors, 2004) we suggest that there must be an appropriate responsive relationship between teachers and learners in order to encourage reflection, and that learners ask reflective questions when they really push their knowledge and understanding about issues.

In our terms, learning can be seen where students make sense of their learning, by cycling backwards and forwards between questioning, feedback and reflection, and then back to action and evaluation. This suggests that students arrive at a comfortable balance between describing, evaluating, exploring and then reflecting as they make sense of their learning and its assessment.

\section{Strategy 6: Enable student autonomy and a sense of ownership}

Ownership for learning is linked to self-regulation as it sees learners as socially, metacognitively and motivationally proactive in their own learning (Zimmerman, 1995). Equally, to participate in the knowledge building community, learners need to take primary responsibility for setting learning goals, accomplishing tasks and selfevaluating their own performances. Teachers need to foster self-regulatory behaviours and self-directed learning, by offering tasks that require both collaborative and independent work.

In our view, designing inquiry-based learning with and for university students develops autonomous problem-solving skills, logical reasoning as well as ownership of learning outcomes. It involves working as a member of a team, questioning, being creative, shaping skills for continued intellectual development. We have argued (Authors, 2005b) that inquiry-based group-work is one of the most important learning experiences because it enables the ownership of theoretical ideas and conceptual change. We see the use of students' questions as essential to shaping these processes, accentuating the comfortable feelings that come from learning and practicing 'real chemistry'. Our 
research has involved groups of students developing a mini-project on, for example, 'Thermochemistry of fitness'.

In this work, data was collected through participant observation of groups, their meetings and their meetings with tutors, analysis of the questions asked by the group in the development of the project (oral and written) and through an oral presentation by the students. The results show that the questions formulated during the development of group mini-projects performed several important functions in the structure of the students' work such as: organising ideas, delimiting the scale of the project, identifying and reflecting on the many strands and sources of information, and in reflecting on the project as a whole. The questions have contributed to students' positive engagement in the discipline, bringing an increase of interaction between teacher and students, an increase in the confidence and trust of the students in the asking of questions, and therefore an increase in the ownership in the learning and teaching of the subject matter.

\section{Strategy 7: Balance both personal and interpersonal orientations}

While learners need to orient themselves to the content domain and course outcomes, they also need to be given scope to discuss the perceived relevance of the course and articulate reasons for taking the course. This can be achieved through conferencing and discussion. The relational element of learning is a product of our desire for affiliation, association and connection (Walther, 1992). Establishing relationships with students online is therefore a priority, while ensuring that students know that sources of help are available.

As a part of this project one of our group devised an intranet system across the department and available to students off-campus. This software system has been accessible through the use of an appropriate password, operating within the building dedicated to the teaching of first year students of Science and Technology. Computers with this software installed were available in the laboratories, in tutorial rooms and in the interconnecting corridors, thus providing free access to students. This enabled those students who had internet facilities outside the university to work at home and access the system. Throughout our work the email system prompted a large number of questions, principally because these students had time, privacy and personal comfort in which to formulate and ask questions.

Online environments provide scope for students to assume multiple participatory roles, enabling varying levels and forms of responsibility for contributing, questioning, 
mentoring and demonstrating expertise, benefiting from social and cognitive aspects of learning online. It is clear, then, that although one student was the author, the question itself was a product of several students' work ('We would like to know...'). The promise was that they would receive feedback response to their questions within a 7-day period, allowing tutors the opportunity to 'bunch' responses to 'frequently asked questions'. This strategy for feedback to the online questions allowed a focus on group problems of understanding, to clarify misconceptions to the group as a whole. Students were also encouraged to provide responses to teacher feedback openly, and engage in dialogue about what forms were most helpful.

\section{Summary and concluding comments}

In this paper we are concerned with university students' questions as they embark upon a search for understanding in their studies. We are particularly interested in oral classroom questions where these signal an open, enquiry-based, dialogic approach to teaching and learning. Our work places the responsibility of questioning onto students rather than their teacher. While this approach brings demonstrable benefits to student learning, we are acutely aware that emotions are heavily involved throughout the process of generating and asking a question.

Our work draws attention to the power of this affective dimension in the formulation and production of questions, in the need for constructive, empathetic response and feedback to students as they ask questions, and some of the evaluated systems in which teachers and curriculum designers in higher education can manage these matters. We have couched the processes of question-asking in terms of CARE, the construction, asking, reception and evaluation of learners' questions. We have also provided seven instructional designs in terms of Vygotskyan zones of proximal development, and drawn out the instructional implications of this new research on teaching and learning. In general, these 'after-CARE' strategies are ones that aim to provide students a 'comfort zone' within which question-asking is seen to be a normal aspect of everydaylearning, that questions are received positively and therefore students are encouraged to formulate good questions in a receptive atmosphere. Our strategies have been developed and used within real-life contexts and have been shown to work.

Among the known tensions in higher education, in most developed countries, lie those between greater individualisation and personalisation on the one hand, and greater 
educative efficiencies on the other. There is, understandably, some difficulty and uncertainty in pursuing student-focused teaching, or attempting to change student perceptions, and these difficulties may be underestimated (see, for example, Cope \& Staehr, 2005; Wilson \& Fowler, 2005). The relations between student perceptions of the learning environment and approach to learning are well-established, but as Prosser \& Trigwell (1999) point out, findings are 'descriptive and analytic, not [...] causal and explanatory' (p.172). Our strategies are attempts to promote the first while managing the second. There is need, of course, to continue testing these strategies and their capacities to encourage and enable student questioning to ensure they continue to meet both needs.

\section{References}

Alsop, S.J. (Ed.) (2005) Beyond Cartesian dualism: encountering affect in the teaching and learning of science. Springer, N1.

Authors (2003)

Askew, S. \& Lodge, C. (2000). Gifts, ping-pong and loops-linking feedback and learning. In S. Askew (Ed.), Feedback for Learning. (pp.1-17). London: Routledge. Assessment and Learning Research Synthesis Group (2002) A Systematic Review of the Impact of Summative Assessment and Tests on Students' Motivation for Learning. Assessment and Learning Research Synthesis Group, Policy and Practice Information and Co-ordinating (EPPI). http://eppi.ioe.ac.uk Accessed 20 June 2004.

Beaty, E., Gibbs, G. \& Morgan, A. (1997). Learning Orientations and Study Contracts. In Marton, F., Hounsell, D.J. \& Entwistle N.J. (Eds.) The Experience of Learning: Implications for teaching and studying in higher education. 3rd (Internet) edition. Centre for Teaching, Learning and Assessment website, University of Edinburgh. http://www.tla.ed.ac.uk/resources/EoL.html.

Bloom, B.S. (Ed.) (1956). Taxonomy of Educational Objectives, the classification of educational goals - Handbook I: Cognitive Domain. New York: McKay

Browne, N. \& Keeley, S.M. (1998). Asking the Right Questions: A Guide to Critical Thinking. New York: Prentice Hall.

Cartney, P. \& Rouse, A. (2006). The Emotional Impact of Learning in Small Groups: highlighting the impact on student progression and retention. Teaching in Higher Education, 11 (1), 79-91. 
Claxton, G. (1991). Educating the inquiring mind: The challenge for school science.

London: Harvester Wheatsheaf.

Dillon, J. T. (1988). The remedial status of student questioning. Journal of curriculum Studies, 20, 197-210.

Chin, C., Brown, D.E. \& Bruce, B. C.(2002). Student-generated questions: a meaningful aspect of learning in science. International Journal of Science Education, 24(5), 521549.

Cope, C. \& Staehr, L. (2005). Improving students' learning approaches through intervention in an information systems learning environment. Studies in Higher Education, 30(2) 181-197.

Curzon-Hobson, A (2003). Higher learning and the critical stance. Studies in Higher Education, 28(2) 201-212.

Fisher R. (1990). Teaching Children to Think. Cheltenham: Nelson Thornes.

Gardner, H. (1999) Intelligence Reframed: multiple intelligences for the $21^{\text {st }}$ Century.

New York: Basic Books.

Graesser, A. C. \& Person, N.K. (1994). Question asking during tutoring. American Educational Research Journal, 31, 104-137.

Graesser, A.C. \& McMahen, C. L. (1993). Anomalous information triggers questions when adult solve problems and comprehend stories. Journal of Educational Psychology, 85, 136-151.

Gipps, C., McCallum, B. \& Hargreaves, E. (2000). What Makes a Good Primary School Teacher? London: RoutledgeFalmer.

Goleman, D. (1996) Emotional Intelligence: why it can matter more than IQ. London: Bloomsbury Publishing Plc.

Good, T.L., Slavings, R.L. Harel, K.H. \& Emerson, M. (1987). Students' passivity: A study of question asking in K-12 classrooms. Sociology of Education, 60, 181-199.

Gunawardena, C. N. (1995). Social presence theory and implications for interaction and collaborative learning and intellectual amplification. International Journal of Educational Telecommunications, 1(2/3), 147-166.

Higgins, R., Hartley, P. \& Skelton, A. (2002). The Conscientious Consumer: reconsidering the role of assessment feedback in student learning. Studies in Higher Education, 27(1), 53-64. 
Hobson, J. (2004). Critical Thinking workshop. Murdoch University 2002. ftp://www.pathguy.com/pub/modula-2/gpm/slearn/resource/crit think/index.html.

Accessed on 04 November 2011

Juwah, C., Macfarlane-Dick, D., Matthes, B., Nicol, D., Ross, D., \& Smith, B. (2004)

Enhancing Student Learning through Effective Formative Feedback. York: Higher Education Academy Generic Centre..

Authors (2004)

Kozulin, A. (2003). Psychological tools and mediated learning. In A. Kozulin, B.

Gindis, V. Ageyev \& S. Miller (Eds.) Vygotsky's educational theory in cultural context. (pp.15-38). Cambridge: Press Syndicate of the University of Cambridge.

Lave, J. \& Wenger E. (1991). Situated learning: Legitimate peripheral participation. Cambridge: Cambridge University Press.

Lemke, J.L. (2003). Talking Science: Language, Learning, and Values. Norwood, NJ: Ablex Publishing.

Marbach-Ad, G. \& Sokolove, P.G. (2000). Good science begins with good questions. Journal of College Science Teaching, 30(3), 192-195.

Marton, F. \& Booth, S.A. (1997). Learning and awareness. Hillsdale, NJ: Lawrence Erlbaum Associates.

May, S., \& Bousted, M. (2004). Investigation of Student Retention through an Analysis of the First-year Experience of Students at Kingston University. Widening Participation and Lifelong Learning, 6(2), 42-48.

Mezirow, J. (2000). Learning as transformation: Critical perspectives on a theory in progress. San Francisco: Jossey-Bass.

Moon J. A (2004). A Handbook of Reflective and Experiential Learning. London, Routledge.

Mortiboys, A. (2002). The Emotionally Intelligent Lecturer. Staff Education and Development Association (SEDA), London.

Nichol, D.J. \& Macfarlane-Dick, D. (2006). Formative assessment and self-regulated learning: A model and seven principles of good feedback practice. Studies in Higher Education, 31(2), 199-218. 
Nicol, D. \& Macfarlane-Dick, D. ( 2004). Rethinking Formative Assessment in HE: a theoretical model and seven principles of good feedback practice. Learning and Teaching Support Network (LTSN). http://www.ltsn.ac.uk/genericcentre/index.asp. Accessed on 13 May 2004.

Orrell, J. (2006). Feedback on Learning Achievement: rhetoric and reality. Teaching in Higher Education, 11 (4), 441-456.

Authors (2004)

Authors (2005a)

Authors (2011, in preparation)

Piaget, J. (1971). Biology and Knowledge. Chicago: University of Chicago Press.

Pizzini, E.L. \& Shepardson, D.P. (1991). Student questioning in the presence of the teacher during problem solving in science. School Science and Mathematics, 91, 348352.

Prosser, M. \& Trigwell, K. (1999). Understanding Learning and Teaching: The experience in higher education. SRHE and Open University Press: Buckingham.

Sadler, D.R. (1989) Formative Assessment and the Design of Instructional Systems. Instructional Science, 18, 119-144.

Salmon, P. (1988). Psychology for Teachers: An alternative approach. London: Hutchinson Education.

Salovey, P. \& Mayer, J. (1990) Emotional Intelligence. Imagination, Cognition, and Personality, 9 (3), 185-211.

Scardamalia, M. \& Bereiter, C. (1996). Computer support for knowledge building communities. In T. Koschman (Ed.), CSCL: Theory and practice (pp. 249-268). Mahwah, NJ: Lawrence Erlbaum.

Smith, E., \& Gorard, S. (2005). Putting Research into Practice: an example from the 'Black Box'. Research Intelligence, 91, 4-5.

Shim, S., \& Ryan, A. (2005). Changes in Self-Efficacy, Challenge Avoidance, and Intrinsic Value in Response to Grades: the role of achievement goals. Journal of Experimental Education, 73 (4), 333-349.

Schon, D. (1987) Educating the Reflective Practitioner, San Francisco: Jossey Bass.

Authors $(2005 \mathrm{a})$

Walther, J. B. (1992). Interpersonal effects in computer-mediated communication: A relational perspective. Communication Research, 19(1), 52-90.

Authors (2006) 
Authors $(2005 \mathrm{c})$

Authors (1997)

Wilson, K. \& Fowler, J. (2005), Assessing the impact of learning environments on students' approaches to learning: comparing conventional and action learning designs, Assessment and Evaluation in Higher Education, 30 (1), pp.87-101

Yorke, M. (2003). Formative Assessment in Higher Education: moves towards theory and the enhancement of pedagogic practice. Higher Education, 45, 477 - 501.

Young, P. (2000). 'I Might as Well Give Up': self-esteem and mature students' feelings about feedback on assignments. Journal of Further and Higher Education, 24(3), 409418.

Van der Meij, H. (1994). Student questioning: A componential analysis. Learning and Individual Differences, 6, 137-161.

Zimmerman, B. (1995). Self-regulation involves more than metacognition: a social cognitive perspective. Educational Psychologist, 30(4), 217-221.

Zoller, U. (2001). Alternative assessment as (critical) means of facilitating HOCSpromoting teaching and learning in chemistry education. Chemistry Education: Research and Practice in Europe, 2 (1), 9-17. 